International Review of Research in Open and Distributed Learning Volume 18, Number 6

September $\mathbf{- 2 0 1 7}$

\title{
A Co-Design Process Microanalysis: Stages and Facilitators of an Inquiry-Based and Technology- Enhanced Learning Scenario
}

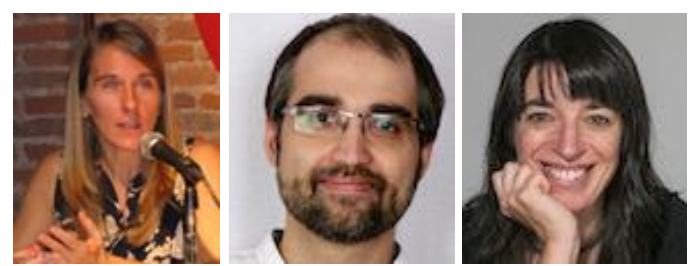

Elena Barbera, lolanda Garcia, and Marc Fuertes-Alpiste

Universitat Oberta de Catalunya, Catalonia, Spain

\begin{abstract}
This paper presents a case study of the co-design process for an online course on Sustainable Development (Degree in Tourism) involving the teacher, two students, and the project researchers. The co-design process was founded on an inquiry-based and technology-enhanced model that takes shape in a set of design principles. The research had two main objectives. Firstly, to identify the moments of change that occur during the co-design process and secondly, to describe the causes and agents that motivate them. This study applied design-based research methodology and used a qualitative approach to collect, analyse, and interpret data. The results show that the co-design methodology led to moderate changes consisting of the progressive construction and refinement of the activities, seeking a sense of continuum throughout by including students' collaboration. The findings also reveal the main role of each of the actors involved. Thus, the teacher focused on basic instructional design related aspects while students focused on improving the use of resources and learning aids. Researchers helped them to embody and achieve the proposed changes and also acted as mediators of pedagogical concepts and vocabulary. CompendiumLD software was a helpful tool to graphically represent and share the prototyping of the activities and to help analyse the design process.
\end{abstract}

Keywords: learning co-design, participatory design, learning scenarios, inquiry-based learning, technology-enhanced learning 


\section{Introduction}

It may seem logical that teachers use implicit approaches, from a predominantly individual perspective, to design courses based on the results of their own effective prior experiences rather than on theoretically articulated intentional principles (Conole, 2010). When thinking about how to guide teachers to increase this intentional and informed application to improve course design, co-design learning processes offer a solution that promotes the user-centred approach (Sanders \& Stappers, 2008). In the field of learning design, processes based on participatory research and action research have proved effective in the classroom while demonstrating strong learning potential as a professional teaching development strategy (Craft \& Mor, 2012). These participatory processes cover important unmet needs in the field of learning design based on collective creation and iterative improvement, which have not yet been fully explored in practice nor have they often been the object of systematic research. Consequently, there are no definitive guidelines for an evolutionary implementation of a co-designed learning scenario that addresses the process of change and thus the collaboration of all agents in the gradual and agreed improvement of the course.

The purpose of this paper is to describe the implementation of a co-design process involving teachers, students, and researchers, by highlighting the moments of change in the learning scenario and their causes, appraising the transitions and inflections during the processes of mutual understanding, negotiation, acquisition, and definition of new perspectives.

More specifically, the intervention analysed in this research involved the co-design of a learning scenario based on inquiry and technology-enhanced learning design principles. The design context corresponds to a pre-existing online course of Sustainable Development in the UOC Degree in Tourism (Universitat Oberta de Catalunya). The study aims to analyse to what extent the co-design methodology and instruments acted as mediators and at the same time proposes a procedure to capture the evolution of a co-design process.

\section{Co-Design of Inquiry-Based and Technology-Enhanced Learning Scenarios}

\section{Co-design as Participatory Design Practice}

Participatory design methods, also called co-design methods, have been used in the educational field in recent years. Roschelle, Penuel, and Schechtman (2006) provide a definition of co-design in education as: "a highly-facilitated, team-based process in which teachers, researchers, and developers work together in defined roles to design an educational innovation, realise the design in one or more prototypes, and evaluate each prototype's significance for addressing a concrete educational need" (p. 606). These authors identify the following characteristics of the co-design processes: (a) they are based on the design of a concrete and tangible innovation; (b) they collect information on educational practice and its context; (c) they have a flexible goal as they involve an iterative implementation process susceptible to being modified; (d) they involve a shared experience among stakeholders that requires a collaborative effort, for example through 
workshops to promote a common understanding between actors; (e) the process has to adapt to the calendar or academic year; (f) it is a well-structured and scaffolded process where each actor has their role and brings valuable knowledge; and (g) the team is led by a principal investigator who is responsible for the success of the process (Penuel, Roschelle, \& Schechtman, 2007; Roschelle et al., 2006).

Many of the practices of co-design in education are associated with the design and implementation of technological tools designed to support learning processes (Hannon, Danahi, Schneider, Coopey, \& Garber, 2012; Mor \& Winters, 2007; Penuel et al., 2007; Roschelle et al., 2006). There are also some experiences and studies where the design object can be the curriculum, the learning materials of a particular course or a methodological model (Könings, Brand-Gruwel, \& Van Merriënboer, 2011; Shrader, Williams, LachanceWhitcomb, Finn, \& Gómez, 2001).

In a review on the topic, Cober, Tan, Slotta, So, \& Könings (2015) analyse the stages in a co-design process from a number of studies (Peters \& Slotta, 2008; Spikol, Milrad, Maldonado, \& Pea, 2009; Zhang et al., 2010) which show that in the early stages of a participatory design process experiences and resources are shared to build a common understanding among the participants. Then a creative development process of the learning scenarios starts using different tools such as concept maps and other tools to prototype the design of tasks and activities (Cober et al., 2015). Other studies show that sketching on paper or in digital format helps to make the design explicit and to share mental representations among different agents (McKenney, Kali, Markauskaite, \& Voogt, 2015).

Some experiences and studies have incorporated students as active participants in the design process. This is the case of a study on the role of higher education students as co-creators of courses which shows that involvement in co-design helps students and teachers gain a deeper understanding of learning processes (Bovill, Cook-Sather, \& Felten, 2011; Healey, Flint, \& Harrington, 2014). Other authors state that collaboration between teachers and students in a process of co-design is positive for developing more informed pedagogical practices and achieving greater collaboration between actors (Cook-Sather, 2014; Könings et al., 2011). Participating in the design and development of activities and technological tools to support collaborative knowledge building can encourage students to show greater responsibility and agency to posing questions, exchanging and critiquing ideas and assessing each other (Cober et al., 2015).

\section{Integrating TEL and IBL Principles into a Learning Scenario Through a Co-Design Process}

This research analyses a learning scenario co-design process conducted by teachers, students, and researchers. The pedagogical model taken as a reference is based on inquiry and technology-enhanced learning (TEL). TEL is a broad term that refers to increasing the effectiveness of learning through the use of technology, facilitating students' involvement in the management of information, processes of critical thinking, and knowledge communication and socialisation (Goodyear \& Retalis, 2010). Designing learning scenarios that integrate TEL principles involves creating knowledge building activities, both individual and group by using shared virtual spaces and asynchronous communication tools (Häkkinnen \& Hämäläinen, 2012). 
IBL is an active learning and student-centred approach in which exploration activity during the research process guides the learning experience (Levy, Aiyegbayo, \& Little, 2009; Maaß \& Artigue, 2013). Implementing the IBL model in higher education activities can improve student performance because it requires greater involvement in the learning process (Spronken-Smith, Walker, Batchelor, O'Steen, \& Angelo, 2012; Zafra-Gómez, Román-Martínez, \& Gómez-Miranda, 2014). In this type of setting, all the resources and learning activities are designed to support the process of research, exploration, and discovery (Levy, 2014).

In order to ensure the foundation of the co-design process in the proposed IBL and TEL model, several design principles were chosen to be reflected as much as possible in the outlined scenario: 1) design principles related with IBL: (a) based on the inquiry process, (b) orientated by problems/questions, (c) active use of the scientific method, (d) centred on and directed by the student, (e) inductive approach to teaching, (f) adaptable teacher support or scaffolding; 2) design principles related with TEL: (a) ICT tools mediate the IBL process, (b) participatory learning, (c) social learning, (d) ubiquitous learning, (e) open learning, (f) personalised and self-directed learning (Gros \& Lopez, 2016). The co-design methodology and instruments were therefore meant to facilitate the integration of these principles in the designed learning scenarios.

Learning design can refer to both a documented product resulting from a design process and to the facilitation of the design process itself. To develop these designs, making them tangible, reflecting on them, and sharing them, a common language is needed to represent them clearly (Laurillard, 2012). There are different types of tools and languages developed for the purpose of facilitating, displaying, reflecting on, and documenting the design process, such as EML, IMS-LD, LAMS, Learning Designer, LDVS, and design patterns. CompendiumLD is an example of such tools, which allows a design or learning activities sequence to be mapped out (a LDVS representation) (Conole, 2010).

Our study aims to contribute to the systematisation and standardisation of the learning design field by showing the systematic recording and representation of the evolution of a co-design process, linked with the reasons and agents that may explain the changes made in the designed learning scenario. The main research question can be therefore formulated as: How does the co-design process unfold and which are the main elements that influence the design and progressive improvement of an inquiry-based and technology-enhanced learning scenario? This general goal is addressed through the following specific research questions: (a) How many and what type of changes occur in the learning scenarios during the codesign process? and (b) What influence do the co-participants and the co-design activities and instruments have on facilitating and scaffolding the co-design process?

\section{Methodology}

This paper focuses on one specific case study taken from a wider research project. This specific case involved the redesign of a Sustainable Development online course of the Tourism Degree offered by the UOC, thus 
delivered through its Virtual Campus. The main goal of the design process was to reformulate the course under the theoretical principles of inquiry-based and technology-enhanced learning. The co-design team in this case study consisted of one teacher, two students, and the members of the research team. Both the teacher and the students volunteered to participate in the research. The teacher was responsible for the design and delivery coordination of the course. Students were following the course while the co-design process took place. None of them had previous experience in co-design or inquiry-based learning.

\section{Co-Design Methodology}

The co-design methodology applied is based on previous research on learning co-design and design models (Cober et al., 2015; Emin-Martinez et al., 2014; Spinuzzi, 2005; Zaphiris, Laghos, \& Zacharia, 2005). The study took place cyclically through five main phases, as shown in Figure 1. Phases A to D consisted of a series of seven participatory workshops in which the teacher in the reported case study collaborated with five teachers from other disciplinary areas, along with members of the research team. The first two workshops were designed to introduce participants to the dynamics of co-design and gain a deeper understanding of the contexts of practice. The next three workshops were more directly orientated to designing the learning scenarios in each context by introducing the inquiry-based and technology-enhanced learning principles. The last two workshops involved prototyping the learning scenarios designed using the storyboarding technique and the Compendium LD program to create a visual representation. In order to support the co-design process and fulfill the goals of each workshop, different activities and representation instruments were used. From phase B to phase D, teachers worked directly on the design of a learning scenario to be applied in their own context, closely supported by at least one or two members of the research group. Throughout the process, they discussed the advantages/disadvantages of different decisions concerning the design of the scenario based on IBL and TEL design principles. 


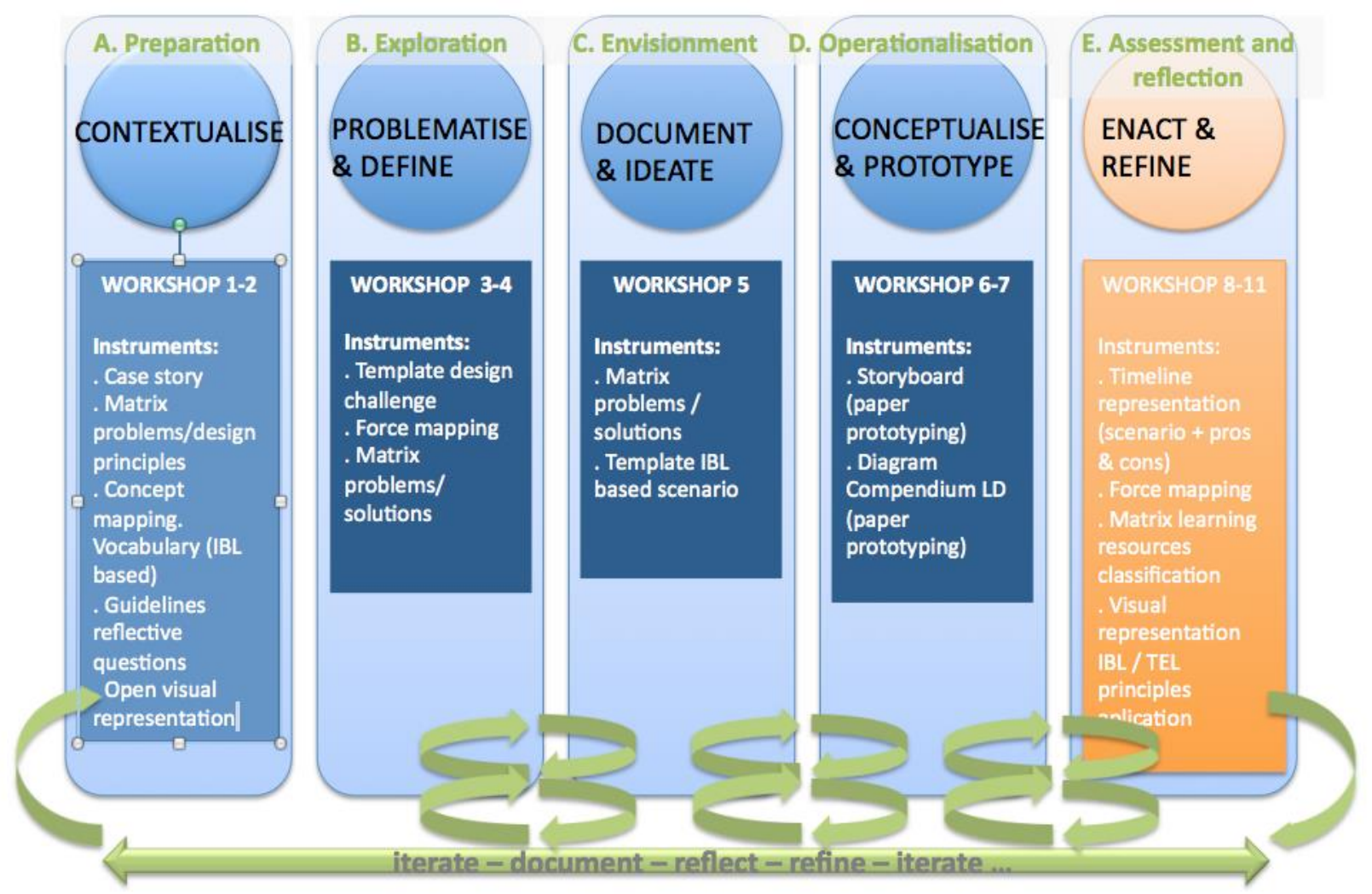

Figure 1. Co-design process embedded in a design-based research framework.

In the final phase of the process (phase E), two students joined the design work groups to critique the prototypes of the learning scenarios designed by teachers, bringing their perspectives and thus validating the final designs based on the enactment of the learning scenario in their corresponding context of practice. Design instruments were used throughout the process to support the understanding of the co-design process among the participants as well as to elicit changes in the learning scenario aligned with the design principles.

\section{The Design-Based Research Approach: Data Collection and Analysis}

This study applies design-based research methodology. This research approach consisted of a participatory and iterative design process where designers collaboratively shaped the concept and the final representation of the learning scenario (Mor \& Winters, 2007). This was done by developing simultaneously contextualised theory on the domain of IBL and TEL pedagogical models as well as on the co-design process itself. A qualitative approach was used for data collection, analysis, and interpretation.

In order to consider the evolution of the designed learning scenario we identified three key moments in the development of the co-design process, corresponding to three different versions of the design product: 1) Version 1: the teacher's initial proposed learning scenario after the preparation and the exploration phases; 2) Version 2: a second more advanced version resulting from interaction between teacher/researchers; here 
a design prototype of the learning scenario is created, corresponding to the envisionment and operationalisation phases; 3) Version 3: includes aspects shared and negotiated with the two students during the implementation of the learning scenario in its real context. In the analysis we address the variations among these three versions and discuss the factors that influenced the observed changes.

For the purpose of the study we used the design artefacts generated by participants during the co-design process.

Design artefacts. A series of artefacts were developed across the workshops using different design instruments: templates, concept maps, matrices and storyboard prototype, among others. These were analysed to better understand the co-design process and to identify the changes between the three versions. Compendium LD tool was one of the main design instruments, used as a prototyping tool of the learning scenario and also as a research tool to build the representation of the learning scenario in its different stages of development during the co-design process, thereby displaying all the changes made from a longitudinal perspective (see Appendix 1 for results).

Observations. The specific goals of the observation process were as follows: (a) to collect the narrative of each co-design session and overall function and visualise the evolution of the process; (b) to collect evidence of behaviours and situations within each working group to express the degree of understanding of the concepts, tools, and procedures, the use and productivity of the procedures and instruments of representation and co-design support, and the joint dynamics of co-design (roles, interventions, conflicts, key issues, phases); and (c) to develop a comprehensive assessment of the session, as well as the adequacy of the co-design process based on the results of the session (elaborated products, productive discussion) and the progress of the learning scenarios. One researcher in the team used an observation template to take notes during the workshops and later completed and improved these notes by listening to each session audio recording. Then, a second researcher, who also listened to the recording, compared the notes. When discrepancies came up they were discussed with a third investigator. Then a content analysis of the collected data was performed by applying a set of content categories that had been previously established as a framework for analysis of the collected data through the various research tools. Through the analysis, the initial set of categories was refined and adapted to the data obtained through the observations. The results were useful for understanding the motives, occasions, agents, and processes of change reflected in the learning scenario throughout the co-design process.

\section{Results}

The modifications identified among the three versions due to the co-design process are detailed in the following three sections.

\section{Description of the Detected Changes}


To cover the first aim, the three versions were compared, analysing the design artefacts produced by the participants in the workshops and also the observations from the workshops. Tables 1 and 2 provide a summary of the type of changes found from V1 to V3.

Table 1

Summary of Changes From V1 to V2

\begin{tabular}{|c|c|c|c|}
\hline $\begin{array}{c}\text { Number } \\
\text { of } \\
\text { changes }\end{array}$ & Dimension & Purpose of the change (instructional action) & Nature of the change ${ }^{1}$ \\
\hline 5 & $\begin{array}{l}\text { A } \\
\text { (Learning aim) }\end{array}$ & $\begin{array}{l}\text { - Align and sequence competencies with collaborative } \\
\text { activities: } \\
\text { - Foster collaboration from the start. Create tool } \\
\text { repository. (Scene 1) } \\
\text { - Encourage collaboration by sharing information. } \\
\text { (Scene 3) } \\
\text { - Shared reflection on sustainability values. } \\
\text { Microblogging. (Scene 5) } \\
\text { - Communicate and discuss results. Presentation tools. } \\
\text { (Scene 8) }\end{array}$ & $\begin{array}{l}\text { Concreteness of the } \\
\text { formulation of } \\
\text { competencies and } \\
\text { expression of specific } \\
\text { learning activities } \\
\text { (W5) }\end{array}$ \\
\hline 5 & $\begin{array}{l}\text { B } \\
\text { (Learning } \\
\text { activity) }\end{array}$ & $\begin{array}{l}\text { - Inclusion of collaborative activities in the course. } \\
\text { - Icebreaker activity. Decide working tools together. } \\
\text { (Scene 1) } \\
\text { - Create resource information repository. (Scene 3) } \\
\text { - Create a space for group interchange/reflection: good } \\
\text { ideas corner. (Scene 5) } \\
\text { - Initial debate before definitive conclusions. (Scene 8) }\end{array}$ & $\begin{array}{l}\text { Concreteness of spaces } \\
\text { for socialising, } \\
\text { interchange and shared } \\
\text { reflection. Organisation } \\
\text { and scheduling. } \\
\text { (W6B2G) } \\
\text { (W6B1E) }\end{array}$ \\
\hline 11 & $\begin{array}{l}\text { C } \\
\text { (Informational } \\
\text { resources and } \\
\text { tools) }\end{array}$ & $\begin{array}{l}\text { - Specify tools, informational sources and didactical } \\
\text { instruments: } \\
\text { - Google Drive. } \\
\text { - Microblogging or wiki. } \\
\text { - } \text { Inforlective debate. } \\
\text { - SWOT document. } \\
\text { - Strategies and actions document. }\end{array}$ & $\begin{array}{l}\text { Resource selection: tools } \\
\text { and didactical and } \\
\text { support instruments } \\
\text { (W6B2E-W6B2D- } \\
\text { W6B1D/J) }\end{array}$ \\
\hline 5 & $\begin{array}{l}\text { D } \\
\text { (Educational } \\
\text { support) }\end{array}$ & $\begin{array}{l}\text { - Reinforce the support between peers and teacher } \\
\text { feedback. } \\
\text { - Initial debate for motivation. } \\
\text { - Peer-assessment. } \\
\text { - Share information resources among students. } \\
\text { - Foster teachers' participation. }\end{array}$ & $\begin{array}{l}\text { Delimit ways of } \\
\text { participation/support } \\
\text { among students in } \\
\text { learning activities and } \\
\text { assessment (W5B1C/D) } \\
\\
\text { Promote and specify } \\
\text { teacher's support } \\
\text { (W5B2G) }\end{array}$ \\
\hline
\end{tabular}

${ }^{1}$ Coding legend used in the obervation template: W= Workshop number; B1= Co-design Dynamic Block; B2= Co-design Process Block; BI= Instruments Block; a,b,c... = item number. Example of codification: W5BID / F: Workshop 5, Instruments Block, item D and F. 


\begin{tabular}{|l|l|l|l|}
\hline 4 & $\begin{array}{l}\text { E } \\
\text { (Learning } \\
\text { outcomes) }\end{array}$ & $\begin{array}{l}\bullet \text { Concreteness of outcomes. } \\
\bullet \text { Collect good ideas. }\end{array}$ & $\begin{array}{l}\text { Specification and } \\
\text { delimitation of outcomes } \\
(\text { W } 7 \text { B1C) }\end{array}$ \\
\hline
\end{tabular}

Table 2

Summary of Changes from V2 to $V_{3}$

\begin{tabular}{|c|c|c|c|}
\hline $\begin{array}{c}\text { Number } \\
\text { of } \\
\text { changes }\end{array}$ & Dimension & $\begin{array}{l}\text { Purpose of the change } \\
\text { (instructional action) }\end{array}$ & Quality of the change \\
\hline o & $\begin{array}{l}\text { A } \\
\text { (Learning aim) }\end{array}$ & - No modifications. & N/A \\
\hline 1 & $\begin{array}{l}\text { B } \\
\text { (Learning } \\
\text { activity) }\end{array}$ & $\begin{array}{l}\text { - Transform social activities into assessment activities } \\
\text { (specifically, debates) and place them in strategic } \\
\text { moments. (W9B2J) }\end{array}$ & $\begin{array}{l}\text { Attribution of value / } \\
\text { reallocation. } \\
\text { (W9B2J) }\end{array}$ \\
\hline 6 & $\begin{array}{l}\text { C } \\
\text { (Informational } \\
\text { resources and } \\
\text { tools) }\end{array}$ & $\begin{array}{l}\text { - Clarify the use of microblogging and introduce it from } \\
\text { the beginning. (W9B2I - W10B2E) } \\
\text { - Shared repository in Drive: Improve its utility by } \\
\text { classifying the references by fields and labelling the } \\
\text { information resources. (W9B2J) } \\
\text { - Introduce Google Scholar to seek more sound } \\
\text { information. (W10B2) } \\
\text { - Introduce a digital SWOT tool. (W1oB2) } \\
\text { - List possible sustainability problems and work } \\
\text { problems. (W1oB2B) } \\
\text { - Informal exchange space for students (social } \\
\text { network). (W10B2) }\end{array}$ & $\begin{array}{l}\text { Qualify new proposals. } \\
\text { (W9B2I/J) }\end{array}$ \\
\hline 5 & $\begin{array}{l}\text { D } \\
\text { (Educational } \\
\text { support) }\end{array}$ & $\begin{array}{l}\text { - Teaching feedback more personalised and in different } \\
\text { formats (audio, text, video). (W9B2I/J - W10B1D - } \\
\text { W1oB2I) } \\
\text { - More direct channel of communication with the } \\
\text { teacher to renegotiate assessment criteria. (W1OB2C) } \\
\text { - Audiovisual presentation of the IBL process. } \\
\text { (W1OB2B/G) } \\
\text { - Illustrate the working process and products. } \\
\text { - Introduce social support elements creating a } \\
\text { supportive community. }\end{array}$ & $\begin{array}{l}\text { Increase and improve the } \\
\text { teaching feedback. }\end{array}$ \\
\hline 1 & $\begin{array}{l}\text { E } \\
\text { (Learning } \\
\text { outcomes) }\end{array}$ & $\begin{array}{l}\text { Delimit and better define the type of final product } \\
\text { (showing examples, list of manageable problems, } \\
\text { etc.). (W1OB2B/E) }\end{array}$ & $\begin{array}{l}\text { Improvement, } \\
\text { delimitation and } \\
\text { definition of the final } \\
\text { product. }\end{array}$ \\
\hline
\end{tabular}

\section{Reasons and Agents Involved in the Changes}

To characterise the changes it may be not sufficient to simply identify what has changed as a result of the co-design process. It is also essential to consider the reasons for the modifications and the agents that facilitate them (Table 3). 
Table 3

Summary of change reasons and agents from $V_{1}$ to $V 2$ and from $V_{2}$ to $V_{3}$

\begin{tabular}{|c|c|c|c|c|c|c|c|}
\hline \multirow[b]{2}{*}{ Dimension $^{2}$} & \multicolumn{3}{|l|}{ From V1 to V2 } & \multicolumn{3}{|l|}{ From V2 to V3 } & \multirow{2}{*}{\begin{tabular}{|l|}
$\begin{array}{l}\text { Design global } \\
\text { referents }\end{array}$ \\
Design \\
Principles \\
IBL/TEL \\
\end{tabular}} \\
\hline & Reason & Agent3 & Instruments & Reason & Agent & Instruments & \\
\hline A & $\begin{array}{l}\text { Reduce drop } \\
\text { outs } \\
\text { (W5BIC) }\end{array}$ & $\mathrm{T}$ & $\begin{array}{l}\text { Template IBL } \\
\text { based scenario }\end{array}$ & - & - & - & $\begin{array}{l}\text { Social learning } \\
\text { (IBL) } \\
\text { Participative } \\
\text { (TEL) }\end{array}$ \\
\hline B & \begin{tabular}{|l} 
Strategically \\
suggest \\
collaboration \\
possibilities and \\
schedule them \\
in a design \\
which aims to \\
achieve more \\
continuous \\
student \\
participation \\
(W6B2G \\
W6B1E)
\end{tabular} & R & Storyboard & $\begin{array}{l}\text { Encourage } \\
\text { participation in } \\
\text { social activities } \\
\text { and add value in } \\
\text { the activity } \\
\text { framework } \\
\text { (W9B2J) }\end{array}$ & S & $\begin{array}{l}\text { Representation } \\
\text { of the scenario } \\
\text { through a } \\
\text { timeline }\end{array}$ & $\begin{array}{l}\text { Active; student } \\
\text { and group } \\
\text { centred; } \\
\text { Inductive } \\
\text { approach (IBL) } \\
\text { Social; } \\
\text { participative and } \\
\text { personalised } \\
\text { (TEL) }\end{array}$ \\
\hline $\mathrm{C}$ & $\begin{array}{l}\text { Identify and } \\
\text { specify tools to } \\
\text { boost } \\
\text { collaboration } \\
\text { (W6BIE) }\end{array}$ & $\mathrm{T}$ and $\mathrm{R}$ & Storyboard & $\begin{array}{l}\text {-Qualify the type } \\
\text { of use of the V2 } \\
\text { tools. } \\
\text { - Propose two } \\
\text { new resources. } \\
\text {-Increase and } \\
\text { improve } \\
\text { didactical } \\
\text { instruments } \\
\text { (educational } \\
\text { support) } \\
\text { (W9B2I/J) }\end{array}$ & $\begin{array}{l}\text { S with R's } \\
\text { help and } \\
\text { negotiation } \\
\text { with T }\end{array}$ & $\begin{array}{l}\text { Representation } \\
\text { of the scenario } \\
\text { through a } \\
\text { timeline }\end{array}$ & $\begin{array}{l}\text { Student and } \\
\text { group centred; } \\
\text { Inductive } \\
\text { approach. } \\
\text { Use of the } \\
\text { scientific method } \\
\text { (IBL) } \\
\text { IBL process } \\
\text { support; } \\
\text { participative and } \\
\text { social (TEL) }\end{array}$ \\
\hline $\mathrm{D}$ & $\begin{array}{l}\text { Leverage } \\
\text { student } \\
\text { participation in } \\
\text { collaborative } \\
\text { spaces as a } \\
\text { monitoring and } \\
\text { peer- } \\
\text { assessment tool } \\
\text { W5B1B/C }\end{array}$ & $\mathrm{T}$ and $\mathrm{R}$ & $\begin{array}{l}\text { IBL based } \\
\text { scenario }\end{array}$ & $\begin{array}{l}\text {-Better define } \\
\text { teaching } \\
\text { support. } \\
\text {-Improve } \\
\text { communication } \\
\text { between } \\
\text { students and } \\
\text { teacher } \\
\text { - Introduce } \\
\text { social support } \\
\text { elements in } \\
\text { community } \\
\text { creation. This is } \\
\text { materialised in } \\
\text { teaching actions } \\
\text { and didactical } \\
\text { tools. }\end{array}$ & $\begin{array}{l}\text { S with R's } \\
\text { help and } \\
\text { negotiation } \\
\text { with T }\end{array}$ & $\begin{array}{l}\text { Representation } \\
\text { of the scenario } \\
\text { through a } \\
\text { timeline }\end{array}$ & $\begin{array}{l}\text { Problem } \\
\text { /question- } \\
\text { orientated; } \\
\text { Use of scientific } \\
\text { method } \\
\text { Teacher and peer } \\
\text { support (IBL) } \\
\\
\text { Participative and } \\
\text { personalised } \\
\text { (TEL) }\end{array}$ \\
\hline
\end{tabular}

${ }^{2}$ Legend: A = Learning Aim; B = Learning Activity; C= Informational Resources and Tools; D= Educational Support; E=Learning Outcomes

3 Legend: $\mathrm{S}=$ Student; $\mathrm{T}=$ Teacher; $\mathrm{R}=$ Researcher; 


\begin{tabular}{|c|c|c|c|c|c|c|c|}
\hline & & & & $\begin{array}{l}\text { (W9B2I/J, } \\
\text { W1oB1D/W1oB2 } \\
\text { I) }\end{array}$ & & & \\
\hline $\mathrm{E}$ & $\begin{array}{l}\text { Incorporate } \\
\text { previous group } \\
\text { work }\end{array}$ & $\begin{array}{l}\mathrm{T} \\
\text { (content) } \\
\mathrm{R} \text { (TEL) }\end{array}$ & $\begin{array}{l}\text { Storyboard \& } \\
\text { CompendiumLD }\end{array}$ & $\begin{array}{l}\text { Clarify the final } \\
\text { product } \\
\text { (W10B2B) }\end{array}$ & $\begin{array}{l}\text { Students } \\
\text { with } \\
\text { researcher's } \\
\text { help }\end{array}$ & $\begin{array}{l}\text { Representation } \\
\text { of the scenario } \\
\text { through a } \\
\text { timeline }\end{array}$ & \begin{tabular}{|l} 
Active and \\
student-driven \\
learning \\
Teacher and peer \\
support (IBL) \\
\\
Participative \\
(TEL)
\end{tabular} \\
\hline
\end{tabular}

\section{Explanation of Differences Between V1-V2-V3 by Dimensions Of Learning Design}

\section{Objectives}

In V1 the teacher indicated that he wanted to reduce the percentage of students dropping out of the course. To do this, he proposed various strategies, including increasing peer support and the students' capacity for collaboration, reinforcing their competencies in this area, as well as their ability to perform a critical analysis of the information. The teacher set three cross-cutting general objectives, and a further four more specific objectives directly linked to each of the four learning activities structuring the students' work. In V2 the teacher restructured the cross-cutting and specific objectives and connected them to nine activity scenes in a much more specific way that focused on developing competencies. This new focus yielded activity transitions that were much more interlinked in the design, clarifying the continuity for the teacher as well as for the students. This in turn enabled, for example, the collaborative competency to be reflected in the activity sequence rather than just mentioned in a cross-cutting objective, which did not specifically materialise in V1. In V3, no changes relating to the learning objectives were included.

\section{Learning Activities}

In V1 the teacher proposed four individual assessment activities. V2 retained the same four fundamental learning activities but the collaboration moments and spaces were reinforced and more precisely delimited, materialising in the form of learning activities with a clearer aim. Thus, each original individual activity from V1 appeared clearly accompanied by a collaborative counterpart which allowed the students to either prepare or communicate actions related with the previously planned individual work. In V2, for example, the individual activity of selecting suitable sources of information was associated with creating a space for collective communication in the class forum where students could share the most useful sources. This activity was linked with the individual gathering of documentation proposed in V1, which became an open and common repository for the entire class group. Thus, it could be said that the learning activities were redistributed, giving greater weight to the collaborative counterpart.

With regard to the changes identified between $\mathrm{V}_{2}$ and $\mathrm{V}_{3}$, the participating students pointed out that certain tasks focused on social interaction between colleagues, such as a couple of debates at the start and end of the activity, did not work as well as hoped. According to them, this was because the debates were not held 
at the right moment and the fact that they were not assessment activities meant they were not awarded the necessary value, so the group did not consider them important which reduced the level of participation. The teacher agreed to incorporate these changes, which were recorded in $\mathrm{V}_{3}$.

\section{Tools and Resources}

The resources proposed in V1 basically consisted of a teaching guide explaining the individual activities, the Virtual Campus's tools, a wiki, an individual repository. In V2, the tools were more concrete and a specific tool was recommended for each activity.

Some collaborative tools were also added to the learning activities. An example of this is the "good ideas corner," a microblogging space where students presented good examples of sustainability for the free use and knowledge of their colleagues, as an aid to producing the work for the subject or to help them in their future jobs. This is the dimension, of the five analysed, in which it could be said that the teacher and researchers visibly negotiated the incorporation of new elements on an equal footing. In the other dimensions it was more often the teacher who proposed changes.

The changes in $\mathrm{V}_{3}$ basically stem from the students pointing out problems identified with the use of certain resources, such as microblogging or Drive, as repositories of information sources. The problems they mention refer either to the lack of clarity regarding the aim of using the resource, or the fact that the use was not practical or did not provide any support for carrying out the activity. The teacher agreed quite closely with the students' analysis and alternatives were proposed for resolving both issues. Moreover, the final workshop included a task which consisted of proposing new digital resources to support the learning scenario and from these two new resources were suggested (SWOT, Google Scholar). Therefore, in this dimension some didactic instruments were included for the purposes of providing educational support, such as examples of other developed projects, a list of possible problems of sustainability to tackle, etc. In this case it was, in fact, the researcher who suggested the specific approach based on the students' comments.

\section{Educational Support}

In V1, only two roles are explained: the course teacher who provided feedback on individual work and the student's peers on the course who provided each other with help and support. In V2, greater detail can be seen: the role of the teacher, while still in the planning phase for the course, breaks down into providing validation feedback, encouraging participation in debates, resolving doubts and guiding.

Support among peers in V2 was detailed in accordance with the changes made at different moments of the process for each task and activity. In V2, this support becomes assessment in pairs, at the initiative of the researchers and seconded by the teacher. It could be said that this is the dimension with the highest concentration of modification proposals between V2 and V3. Fundamentally, this is due to the students' insistence on the need to increase and improve communication between the teacher and students, especially as a means of providing formative feedback on their working process to refocus them in the right way. With the aid of the researcher and the teacher's explanations, the response to this need started to take shape in 
possible assistance actions, such as: specifying more personalised teacher feedback channels, creating an audio-visual presentation of the learning scenario that clearly explained the work proposal based on IBL, providing a clearer thread to connect the social content tasks to create a support community to motivate and accompany the students during the course, etc.

\section{Learning Results}

In $\mathrm{V} 1$, the results of the individual activities were identified with their corresponding percentages in the continuous assessment, but it was observed that the collaborative part of participation in group activities did not earn students a quantitative grade.

In V2, the learning products corresponded to the four individual activities the students were required to hand in and this did not change. However, other non-directly assessed activities were added which served as the start or intermediate step towards these four activities being handed in, such as, participation in an initial debate to share the problem to be worked on or provide a previous presentation of work results in the class forum in order to receive/offer feedback for the final presentation. Corresponding to a more continuous design for the course that is more coherent with an IBL approach, group scenes of joint reflection on information sources were added to the forum, as well as a shared spreadsheet with tools for working on the subject. Thus, this learning results section rebalances the assessment of the individual part and the group part.

In this section, the roles of the teacher and the researchers were significantly different. Therefore, with the aim of obtaining a more motivating and active assessment approach in accordance with the ultimate goal of maintaining the bond between the students to avoid drop-outs, the teacher pushed through the changes most related to the learning content, while the researchers made more contributions focused on the use of technology and on the type of learning evaluation.

In this last dimension, only one modification was found in $\mathrm{V}_{3}$ which was related with the previous dimension. At the students' suggestion, it was decided to look for mechanisms to clarify the expected result.

\section{Discussion}

The discussion is organised into three key points that bring together the main findings and observations in terms of influence and change in the co-design process, thus answering the main formulated research question.

\section{Learning Scenarios as a Result of the Co-Design Process}

The former scenario was already quite well adjusted to the IBL model. Therefore, the co-design process did not involve designing the learning scenario from scratch, nor creating a disruptive reconstruction. Rather, it sought to strengthen, define, and/or refine certain elements from reflection and decision-making on the 
roles in the general scenario design. In Latour's terms, collaborative design "is never a process that begins from scratch: to design is always to redesign (Voogt et al., 2015),

The co-design process is situated. It starts in its own real context, both physical and social (Cober et al., 2015; Voogt et al., 2015). This starting point facilitated and sped up the process, but also hindered the introduction of deeper or more disruptive changes. These aims also complicated the integration of certain new elements, because they needed to adapt and fit into the existing structure, trying to avoid excessively distorting the initial proposal. Sometimes this created tensions between the adopted decisions that may turn out to be problematic due to a lack of consistency with the overall proposal. These tensions can be found in the dynamics of co-design that emerge when engaging users in the process as they play different roles, share different points of view, and depend on time and productivity constraints (Leary et al., 2016; Penuel et al. 2007; Roschelle et al., 2006). Thus, we speak of moderate changes, of small aspects, initially focused on the formulation of certain activities, more collaboratively driven and addressed mainly by introducing certain resources that mobilise more methodological or conceptual aspects.

Moreover, if we assess the extent to which the design principles proposed in the project as a reference are shown in the scenario, we see that those related to IBL are, for the most part, more clearly reflected in the scenario than those related to TEL. It seems that the co-design process was more effective in supporting reflection on the principles more directly linked to the methodological model, while the use of technology was not integrated in the reflection so naturally. Perhaps the reason is that TEL design principles referred to issues emphasising different aspects (such as open, ubiquitous, self-directed, or collaborative learning) and the broad scope made it difficult to obtain concrete changes related with the different aspects proposed (see Gros \& Lopez (2016) for an extended explanation of TEL design principles applied in the project).

\section{Roles and Functions of the Agents Involved in the Co-Design Process}

In the process of co-design each actor has their role and brings valuable knowledge (Penuel et al., 2007; Roschelle et al., 2006). On the role of the various actors involved in the co-design process, it is clear that the contributions of the teachers, students, and researchers have their own particular perspective based on their own needs, interests, and expectations and the co-design process helped raise awareness of the components of the teaching and learning scenario (Conole, 2013).

The teacher generally assumed the role of the first agent of change, focusing on more basic instructional design issues (formulation of competencies and learning objectives, proposing new activities and resources, etc.). The co-design methodology and structure helped the teachers to be more aware of the interconnected nature and the mutual influence of all design principles and features (Leary et al., 2016). The contributions of the students, however, focused primarily on improving or refocusing the use of learning resources and intensifying and improving the teaching support mechanisms, always starting from identified problems or questionable issues. Finally, the role of researchers is usually to help turn the teachers' and students' observations into well-defined proposals and provide conceptual frameworks to describe the issues and support decision-making. 
In the case of students, it was sometimes difficult to focus the discussion specifically on the learning scenario because they tended to discuss the educational model of the university. In general, there was constructive dialogue among the three parties, although some of the students' proposals were not implemented because they were not viable in the short term. At other times, the students' excessively rigid preconceptions prevented them from openly evaluating various alternatives or solutions.

The role of the researcher was, as foreseen, accompanying and giving support: mediating for better understanding between the other two agents (teachers and students), clarifying the meaning of the pedagogical concepts that came up, helping to give concrete form to the ideas of both parties, identifying potential difficulties or shortcomings of the scenarios outlined in each of the phases, trying to bring the proposals to the design principles of reference, etc. Moreover, the experience in the project led the researcher to progressively take a leading and conducting role in the co-design sessions. This role was hard to take on at first, because of the difficulty of striking a balance between playing a supportive role and not being too intrusive or excessively determining the participants' decisions. However, this balance was gradually achieved.

\section{Methodology and Co-Design Instruments}

The co-design methodology employed acted as a mediator in the process, leading to the progressive construction of learning scenarios that were refined through various iterations and the involvement of the different actors in each version. Thus, the proposed methodology, through workshops and activities, allows the definition and progressive realisation of the learning scenario through an awareness process supported by reflection among all the actors involved. According to Cober et al. (2015) and Penuel et al. (2007) this type of methodology enables a creative process and collaborative understanding.

Beyond deciding what changes should be made in the design process, and even how to explain these changes, some difficulties were observed in identifying, setting, and consolidating some of the modifications. Once the changes are decided, it is important to verify that they are reflected explicitly, for example in the syllabus, and that they are finally implemented in practice for further assessment. Sometimes it is difficult to identify and bring the changes to life in the design scenario, which can eventually lead to a gap between the agreements reached in the co-design process and their subsequent implementation.

Therefore, tools for visualising the adopted changes have been particularly useful in this case, especially CompendiumLD (Conole, 2010). This tool was used for two purposes: (a) to support the prototyping of learning scenarios during the co-design process, and (b) to support the analysis of the versions explained in this study. In both cases, the tool requires each change to be defined and specifically captured, which involves taking a series of decisions based on parameters such as location, name, category, and nature of the change as well as how it relates to and affects the other design elements in which it is embedded. In this regard, the flexibility of CompendiumLD allowed it to be easily adapted to our purposes, but it may result in a certain arbitrariness in deciding how specific elements are represented since there are no pre-set parameters. This process served to highlight the value of using different kinds of support instruments to 
provide a common and shared representation of the scenario from which views can be contrasted and to help realise and enhance decision making on changes to be made, with the aim of progressively improving the design of the learning scenario.

\section{Practical Implications and Suggestions for Future Research}

This section briefly outlines some practical recommendations to successfully drive and research co-design processes of inquiry-based and technology-enhanced learning scenarios:

- Considering the observed difficulty in integrating the TEL design principles into the designed scenarios, it would be necessary to work on them in greater depth with teachers and students involved in the co-design process. It is important that these principles are understood in order to see the range of tools available, how they work, what their learning affordances are, how they can be embedded in the activities, etc. In doing so, technology can be better integrated into the designed learning scenarios. Another strategy in this regard would be to work on TEL design principles in a more integrated manner with IBL ones. There are several design instruments that would allow this, such as design patterns integrating both IBL and TEL perspectives.

- Establishing verification mechanisms may be useful for checking that the decisions taken in the codesign process involving changes to the activities have really been implemented in the learning scenarios. Those procedures could consist of explicit charts or representations of the agreed changes in the learning scenario following each step of the process that could be checked by every participant. The use of tools such as CompendiumLD could be of help in supporting this activity.

- The role of researchers is very important for ensuring that the optimum conditions are maintained when applying the co-design methodology. As said, this role requires a balance between guidance and support in the process and avoiding excessive interventionism, as both the final decisions on the design and the justification for these decisions should preferably come from participants, since they are ultimately responsible for the designed learning scenarios. However, we must stress the relevance of researchers' leading role in the co-design process. Apart from the researcher who acts as moderator and directs the different steps of the process in accordance with the established methodology, the researchers directly involved in the co-design of learning scenarios had to take an active role in making suggestions for improvement, posing questions, anticipating problems, and to a certain extent driving the process in order to ensure progress. It is important that these matters are discussed within the research team, in order to maintain a consistent and shared position in the different groups of co-designers.

- For discussions to be significant and have an effective impact on the design, they must be continuous and constant and involve all the participants in the process. It is essential to effectively integrate the cycle of co-design into course development, taking into account that the process is 
highly conditioned by calendar constraints (Roschelle et al., 2006), by the participants' availability and their willingness to remain engaged. Ideally, the co-design cycle should be continued until the team considers that the designed learning scenario is good enough, so it is a long-lasting process that needs to adapt to the context pace and eventualities.

- Some of the main limitations of the study were the difficulty of keeping track of the influence of context variables on the intervention, as well as the heavy reliance on participants' involvement. In this sense, although it was not the focus of our study, the experience made us aware of the importance of considering the context and shared understandings of practice among all agents involved in co-design. As stated by Hundal, Levin, and Keselman (2014), we must appreciate teachers' and students' framing as a valid stance based on their experiences and take the constraints teachers experience more seriously, bearing in mind that their systemic expectations may be different to those of researchers, such as: the need to retain students' interest, the importance of content and time pressure to finish the curriculum provisions.

- As one of the frequent criticisms against DBR, another difficulty was combining the progressive design refinement with the data gathering and analysis activity in an integrated way with theory development. The conjecture mapping method proposed by Sandoval (2014) provides a DBR structure that might be of help to overcome these limitations. This method intends to articulate and to map the conjectures about design and the theoretical ideas supporting them, embodied in a learning environment.

\section{References}

Bovill, C., Cook-Sather, A., \& Felten, P. (2011) Students as co-creators of teaching approaches, course design and curricula: implications for academic developers. International Journal for Academic Development 16(2). pp. 133-145. http://dx.doi.org/10.1080/1360144x.2011.568690

Cober, R., Tan, E., Slotta, J., So, H-S., \& Könings, K. D. (2015). Teachers as participatory designers: two case studies with technology-enhanced learning environments. Instructional Science, 43(2), 203. doi: $10.1007 / \mathrm{s} 11251-014-9339-0$

Conole, G. (2010). Learning design - Making practice explicit. ConnectEd 2010: 2nd International conference on Design Education, Sydney, Australia.

Conole, G. (2013). Designing for learning in an open world. New York: Springer. 
A Co-Design Process Microanalysis: Stages and Facilitators of an Inquiry-Based and Technology-Enhanced Learning Scenario Barbera, Garcia, and Fuertes-Alpiste

Cook-Sather, A. (2014). Multiplying perspectives and improving practice: what can happen when undergraduate students collaborate with college faculty to explore teaching and learning. Instructional Science, 42(1), pp. 31-46. doi: http://dx.doi.org/10.1007/s11251-013-9292-3

Craft, B., \& Mor, Y. (2012). Learning Design: reflections upon the current landscape. Research in Learning Technology, 20. doi: http://dx.doi.org/10.3402/rlt.v20io.19196.

Emin-Martinez, V., Hansen, C., Rodríguez Triana, M. J., Wasson, B., Mor, Y., Dascalu, M., ... \& Pernin, J.P. (2014). Towards teacher-led design inquiry of learning. eLearning Papers (36).

Goodyear, P., \& Retalis, S. (2010). Learning, Technology and Design. In P. Goodyear \& S. Retalis (Eds.), Technology-Enhanced learning (pp. 1-28). Rotterdam: Sense Publishers.

Gros, B. \& López, M. (2016). Students as co-creators of technology-rich learning activities in higher education. International Journal of Educational Technology in Higher Education, 13. DOI: 10.1186/s41239-016-0026-x

Häkkinnen, P., \& Hämäläinen, R. (2012). Shared and personal learning spaces: Challenges for pedagogical design. Internet and Higher Education, 15(4), pp. 231-236.

Hannon, D., Danahy, E., Schneider, L., Coopey, E., \& Garber, G. (2012). Encouraging teachers to adopt inquiry-based learning by engaging in participatory design. IEEE 2nd Integrated STEM Education Conference, Ewing, NJ, USA. doi:10.1109/isecon.2012.6204169

Healey, M., Flint, A., \& Harrington, K. (2014). Engagement through partnership: students as partners in learning and teaching in higher education. The Higher Education Academy. Retrieved from ttps://www.heacademy.ac.uk/engagement-through-partnership-students-partners-learning-andteaching-higher-education

Hundal, S., Levin, D.M., \& Keselman, A. (2014) Lessons of researcher-teacher co-design of an environmental health afterschool club curriculum. International Journal of Science Education, 36(9), 1510-1530. DOI: 10.1080/09500693.2013.844377

Könings, K. D., Brand-Gruwel, S., \& Van Merriënboer, J. J. G. (2011). Participatory instructional redesign by students and teachers in secondary education: effects on perceptions of instruction. Instructional Science, 39(5), 737-762. http://dx.doi.org/10.1007/s11251-010-9152-3

Laurillard, D. (2012). Teaching as a design science. Building pedagogical patterns for learning and technology. New York and London: Routledge.

Leary, H., Severance, S., Penuel, W.R., Quigley, D., Sumner, T., \& Devaul, H. (2016). Designing a deeply digital science curriculum: Supporting teacher learning and implementation with 
A Co-Design Process Microanalysis: Stages and Facilitators of an Inquiry-Based and Technology-Enhanced Learning Scenario

Barbera, Garcia, and Fuertes-Alpiste

organizing technologies. Journal of Science Teacher Education, 27, 61-77.

doi:10.1007/s10972-016-9452-9

Levy, P. (2014). Technology-supported design for inquiry-based learning. In M. Li \& Y. Zhao (Eds.), Exploring learning \& teaching in higher education (pp. 289-304).Berlin Heidelberg: Springer.

Levy, P., Aiyegbayo, O., \& Little, S. (2009). Designing for inquiry-based learning with the learning activity management system. Journal of Computer Assisted Learning, 25(3), 238-251.

http://dx.doi.org/10.1111/j.1365-2729.2008.00309.x

Maaß, K. \& Artigue, M. (2013). Implementation of inquiry-based learning in day-to-day teaching: a synthesis. ZDM - The International Journal on Mathematics Education, 45(6), 779-795. http://dx.doi.org/10.1007/s11858-013-0528-0

McKenney, S., Kali, Y., Markauskaite, L., \& Voogt, J. (2015). Teacher design knowledge for technology enhanced learning: an ecological framework for investigating assets and needs. Instructional Science, 43(2), 181-202. http://dx.doi.org/10.1007/s11251-014-9337-2

Mor, Y., \& Winters, N. (2007). Design approaches in technology enhanced learning. Interactive Learning Environments, 15(1), 61-75. http://dx.doi.org/10.1080/10494820601044236

Penuel, W. R., Roschelle, J., \& Shechtman, N. (2007). Designing formative assessment software with teachers: An analysis of the co-design process. Research and Practice in Technology Enhanced Learning. 2(1), 51-74. http://dx.doi.org/10.1142/s1793206807000300

Peters, V. L., \& Slotta, J. D. (2008). Co-designing a knowledge building activity with secondary school biology teachers. Retrieved from http://www.ikit.org

Roschelle, J., Penuel, W. R., \& Schechtman, N. (2006). Codesign of innovations with teachers: Definition and dynamics. ICLS 'o6 Proceedings of the 7 th international conference on Learning sciences (pp. 6o6-612). Bloomington, IN. Retrieved from http://dl.acm.org/citation.cfm?id=1150122

Sanders, E. B., \& Stappers, P. J. (2008). Co-creation and the new landscapes of design. CoDesign: International Journal of CoCreation in Design and the Arts, 4(1), 5-18. http://dx.doi.org/10.1080/15710880701875068

Sandoval, W. (2014) Conjecture mapping: An approach to systematic educational design research. Journal of the Learning Sciences, 23(1), 18-36.

Shrader, G., Williams, K, Lachance-Whitcomb, J., Finn, L-E., \& Gómez, L. (2001) Participatory design of science curricula: The case for research for practice. Annual Meeting of the American Educational Researchers' Association, Seattle, Washington. Retrieved from https://www.researchgate.net/publication/313616039_ 
A Co-Design Process Microanalysis: Stages and Facilitators of an Inquiry-Based and Technology-Enhanced Learning Scenario

Barbera, Garcia, and Fuertes-Alpiste

Spikol, D., Milrad, M., Maldonado, H., \& Pea, R. (2009). Integrating co-design practices into the development of mobile science collaboratories. Ninth IEEE international conference on advanced learning technologies (pp. 393-397). IEEE. doi:10.1109/ICALT.2009.175

Spinuzzi, C. (2005). The methodology of participatory design. Technical Communication, 52(2), 163-174. Retrieved from https://faculty.washington.edu/socha/css572winter2012/spinuzzi\%20methodology\%20of\%20pa rticipatory\%20design\%20s5.pdf

Spronken-Smith, R., Walker, R., Batchelor, J., O’Steen, B., \& Angelo, T. (2012). Evaluating student perceptions of learning processes and intended learning outcomes under inquiry approaches. Assessment \& Evaluation in Higher Education, 37(1), 57-72. http://dx.doi.org/10.1080/02602938.2010.496531

Voogt, J., Laferrière, T., Breuleux, A., Itow, R. C., Hickey, D. T., \& McKenney, S. (2015). Collaborative design as a form of professional development. Instructional Science. 43, 259-282. doi: 10.1007/s11251-014-9340-7

Zafra-Gómez, J. L., Román-Martínez, I., \& Gómez-Miranda, M. E. (2014). Measuring the impact of inquiry-based learning on outcomes and student satisfaction. Assessment \& Evaluation in Higher Education, 4O(8), 1-20. doi: 10.1080/02602938.2014.963836

Zaphiris, P., Laghos, A., \& Zacharia, G. (2005). An overview of distributed construction through participatory design. In M. Khosrow-Pour (Ed.), Encyclopedia of information science and technology (pp. 902-906). IGI Global, Hershey, PA.

Zhang, B.H, Looi, C.K., Wong, L. H., Seow, P., Chia, G., Chen, W., ... \& Soloway, E. (2010). Deconstructing and reconstructing: Transforming primary science learning via a mobilized curriculum. Computers \& Education, 55(4), 1504-1523. doi:10.1016/j.compedu.2010.06.016. 


\section{Appendix 1}

\section{CompendiumLD Representation V1}

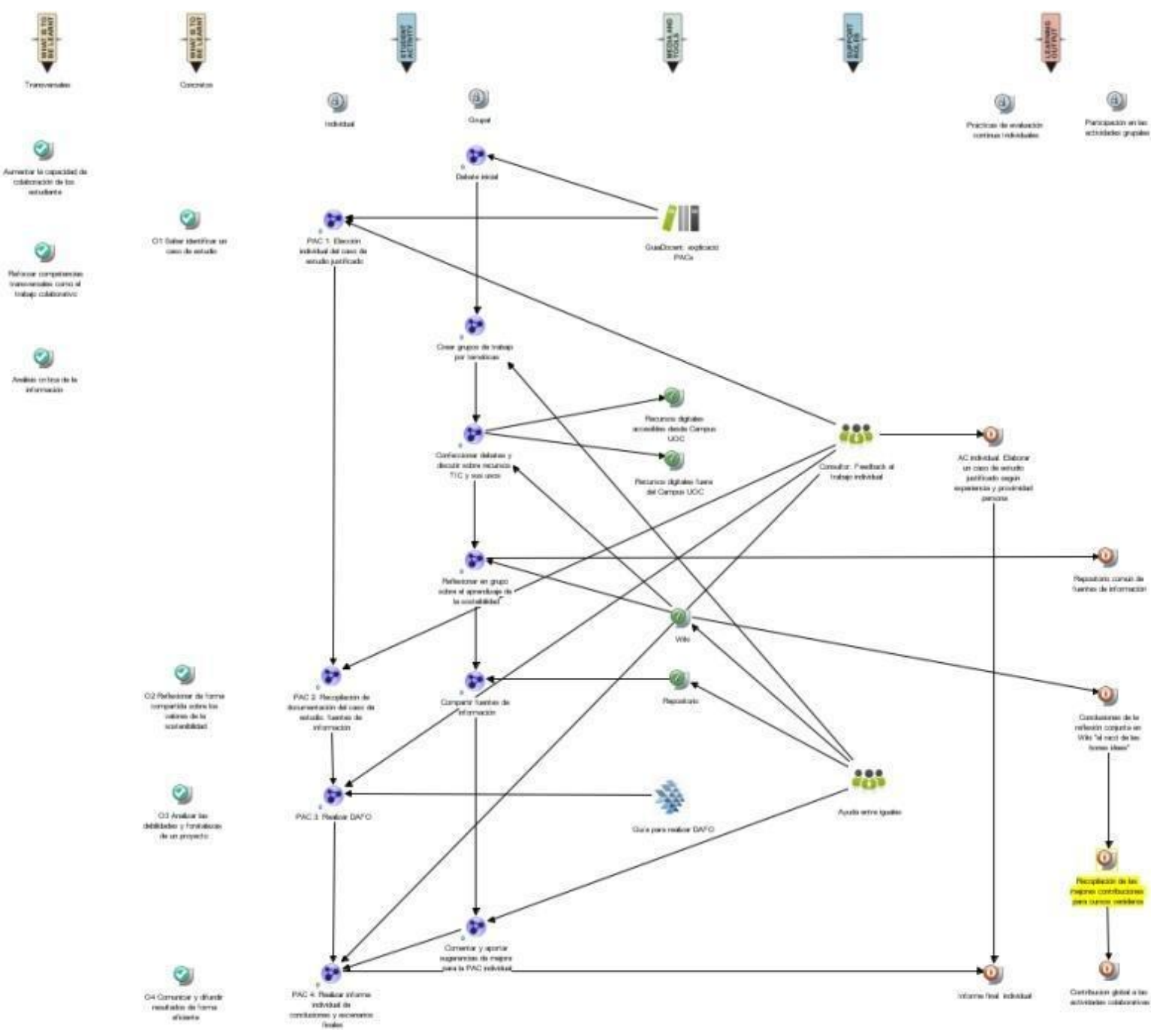




\section{CompendiumLD Representation V3}

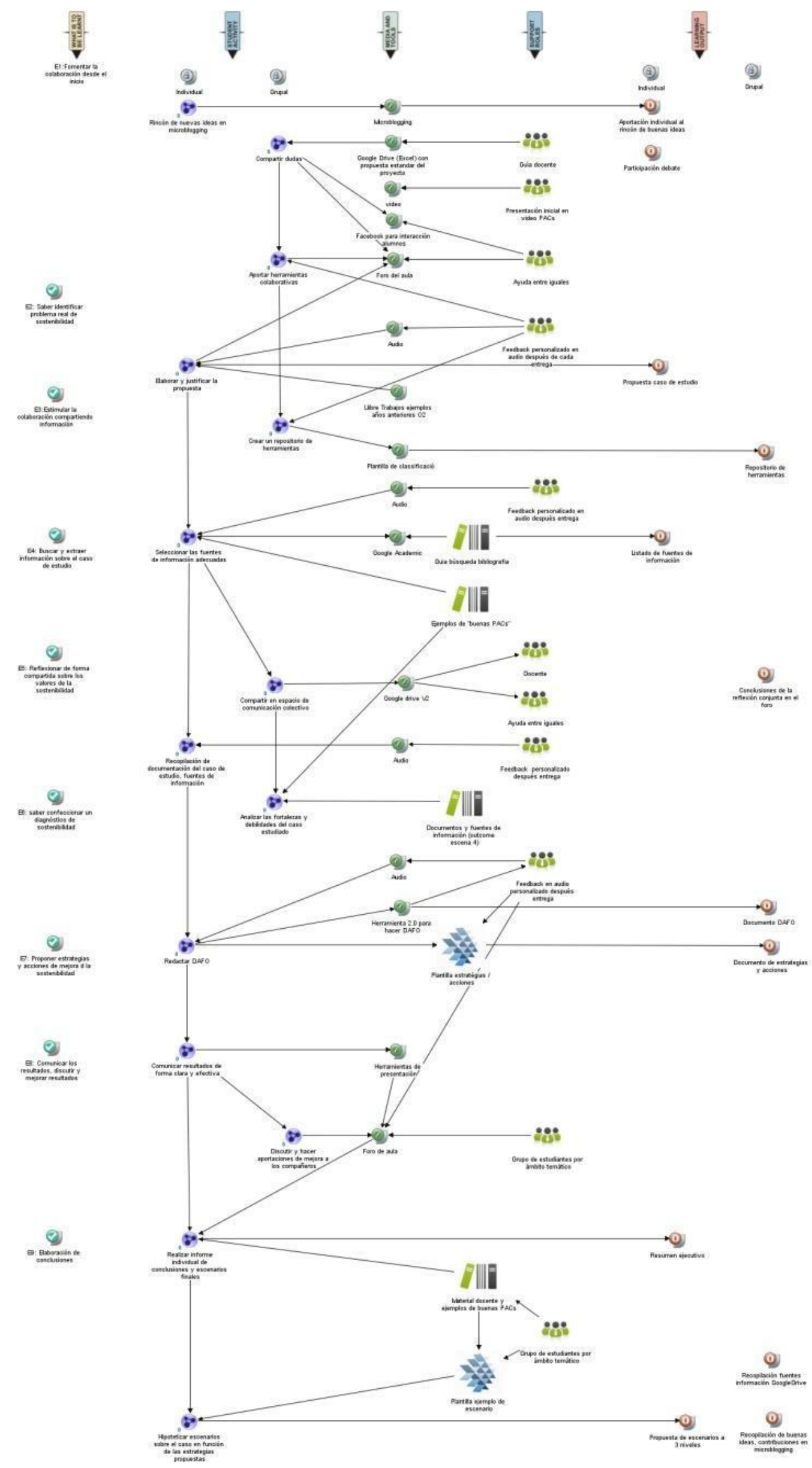


A Co-Design Process Microanalysis: Stages and Facilitators of an Inquiry-Based and Technology-Enhanced Learning Scenario Barbera, Garcia, and Fuertes-Alpiste

Athabasca

University

(c) (D) 